\title{
Goal - Driven "Five - in - one" Teaching Model Integrating Research and Practice into Mathematics Teaching Courses in Agricultural Universities
}

\author{
Zhang LIU \\ College of Sciences \\ Jiangxi Agricultural University \\ Nanchang 330045, P. R. China \\ Yi WEI \\ Institute of Education \\ Jiangxi Agricultural University \\ Nanchang 330045, P. R. China
}

\author{
Guiying FANG*, \\ College of Sciences \\ Jiangxi Agricultural University \\ Nanchang 330045, P. R. China \\ Canhua LI \\ College of Sciences \\ Jiangxi Agricultural University \\ Nanchang 330045, P. R. China
}

\begin{abstract}
With the continuously expansion of colleges and universities, China's higher education has already turned the original "elite education" to "popular education", but at the same time it also brings new problems of wide distribution and uneven quality about the students. In the mathematics teaching in agricultural universities, according to the different qualifications of students for different education, hierarchical teaching is the key to solve these problems. Through long-term teaching practice, Jiangxi Agricultural University aims to "improve the quality of talent development" and implements the "Five-in-one" hierarchical teaching model from five aspects of the goal-driven, which is "meeting the needs of social development, adapting to the characteristics of agricultural universities, grasping the construction of professional connotation, promoting innovation in the characteristic field, and emphasis on developing the practical ability", and integrate it into the teaching system of mathematics. It promotes the continuously improvement of teaching level and achieves the comprehensive and coordinated development of teaching quality and talent training quality, and also has some reference functions to the teaching of mathematics course in other colleges and universities.
\end{abstract}

Keywords-Five-in-one; Hierarchical teaching; Talent training quality; Comprehensive evaluation

\section{INTRODUCTION}

In recent years, due to the continuous expansion of colleges and universities, the gross enrollment rate of China's higher education has been greatly improved. Yubo Du, the minister of Chinese education at the time, said at the "Twelfth Five-year Education Work Conference" that the gross enrollment rate of China's higher education reached $26.5 \%$ in 2010, and it was predicted that this proportion would reach $36 \%$ by 2015 . In addition, according to the "China Higher Education Quality Report" [1] released by the Higher Education Teaching Evaluation Center of the Ministry of Education in January 2016 the number of students in our country reached 37 million in

Research topic on reform of higher education in Jiangxi province (JXJG16-3-18), and the Science and Technology Planning Project of Jiangxi Provincial Education Department (GJJ150401, 160410)
2015, ranking first in the world, with a gross enrollment rate of $40 \%$, which was higher than the global average. These figures show that China's current higher education has changed from the original "elite education" to "popular education." However, with the continuous expansion of colleges and universities, the scope of students gradually expanded and the college admissions scores declined, which makes the deep gap between the overall quality of students and the quality of students has become uneven.

In order to solve the possible contradiction between the number of students and the quality of teaching, the hierarchical teaching method is currently a feasible teaching reform direction. In the Song Dynasty of our country, the great educator $\mathrm{Xi}$ Zhu proposed the idea of teaching students in accordance with their aptitude when summarizing Confucius' teaching methods. Modern hierarchical teaching theory originated in the United States from the end of the 19th century to the early 20th century. It mainly solves the disadvantages of the traditional class teaching model which can hardly take care of individual differences, and is a great innovation in the form of teaching organization [2]. However, if the "layered" process is unreasonable, the self-esteem of the students will be affected, and some of them will even affect the self-confidence of learning in the future [3-6]. The high degree of development of the information society today requires the further refinement of the social division of labor and the need for more talents with different capabilities and levels. Agricultural colleges and universities, which are an important part of higher education, have their own characteristics due to their student conditions, professional disciplines, training objectives, social needs, and student development orientation. Therefore, more in-depth explorations and researches of hierarchical teaching models are needed. By reviewing the teaching practice of mathematics curriculum in Jiangxi Agricultural University, this article summarizes the contents of the five-dimensional tiered teaching reform based on goal-driven "major education" for mathematics curriculum in our school in recent years, the 
implementation plan for reform, the phased achievements of the reforms. Its features and applications provide some references for improving the quality of innovation talents in the new situation.

\section{RESEARCH CONTENT}

In colleges and universities, teaching is the basis of all work, and improving the quality of teaching is an eternal theme of colleges and universities. Since the period of popular education, Jiangxi Agricultural University has over ten years of university mathematics teaching reforms, has broken through the single form of traditional classroom teaching, combined with the characteristics of agricultural institutions of higher learning, summed up the outstanding results formed in teaching practice, and "enhanced the quality of personnel training. "To achieve the objective, to implement the goal-driven "five-dimensional," one-level teaching model in the following five aspects: "Connecting social development needs, adapting to the characteristics of agricultural colleges and universities, grasping the connotation of professional connotations, promoting innovation in characteristic fields, and emphasizing practical ability cultivation." And it is integrated into the teaching system of mathematics courses. In the ongoing teaching reform and practice, the teaching quality and personnel training quality of agricultural colleges and universities are continuously improved.

\section{A. Target stratification: Match social development needs and cultivate excellent talents for the society.}

Aiming at the fact that students of our university have a wide distribution of students, a large number of admission scores, and a large number of subject specialties, a scientific analysis of their needs and requirements in the teaching practice of mathematics courses is carried out. According to the different orientations of disciplines and the basic requirements of the syllabus And, formulate corresponding teaching plans from different levels, and at the same time formulate matching layered teaching goals according to the level of student's student source quality. For example, for those students who are studying at higher institutions as their goal, while consolidating and deepening the knowledge of books, they will also add some more difficult knowledge exercises to them to grasp the training of these students' self-learning ability and mathematics application ability. In addition, for students who have different interests in different mathematics directions, our school offers very practical mathematics required courses or elective courses, or introduces students into a certain field by means of the lecture. On the one hand, students are allowed to broaden their horizons, expand their knowledge and improve their mathematical analysis skills. On the other hand, students are fully aware of the important role of mathematics in the development of society and recognize that "mathematics is on our side" and mathematics is the solution to our work. A powerful tool for encountering problems in life is to promote student self-learning and self-improvement. In practice, our school has established "Mathematics" and "Economic Mathematics" courses for information and computing science majors, economics, etc., and "biology mathematics" courses for biology majors. The school has established "Modern
Mathematical Methods." The results prove that all have received good results, and promote the development and employment of students in related fields. Of course, teachers will also help students understand the professional knowledge of mathematics needs, guide students to gradually establish their own career planning, and combine their own actual situation, to develop their own mathematics learning goals.

\section{B. Student Stratification: Adapting to the characteristics of agricultural colleges and universities, cultivating specialized talents adapted to the characteristics of agricultural colleges and universities.}

Since the party's 18th National Congress, the issue of ecological civilization construction and environmental protection has been elevated to a new historical height. This requires higher education institutions in China, especially higher agricultural colleges, to vigorously upgrade their teaching quality and the quality of personnel training so as to cultivate ecological environmental protection fields. Innovative high-tech talents; therefore, in cultivating the mathematical and analytical abilities of agricultural college students, we divide the students into mathematics classes at different levels from three aspects of students' cognitive structure, logical analysis ability, and subjective initiative. In the teaching practice, we found that the knowledge of mathematics theory of students in higher agricultural colleges and universities was uneven. Some students of arts and sciences students led to differences in the level of students' knowledge in mathematics. The students have the ability to understand the basic courses, logical thinking skills, and practical hands-on problem solving. Some students with a good mathematical background lack the ability to combine the basic knowledge with the problems encountered in practice to solve problems. However, some students with insufficient theoretical knowledge of mathematics have the advantage of having stronger hands-on capabilities in practice. Facing such students from higher agricultural colleges and universities, if they do not consider the actual level of students, they all adopt the same teaching content and make the same requirements. Using a test paper to target all students is obviously not in line with the students' multiple levels. Therefore, for a period of time, we have implemented layered teaching based on "study of the situation". The "situation" here includes basic conditions such as students' knowledge structure, ability basis, learning initiative, and interest in learning [7-8]. The dominant role in teaching and the main role of students are very important. Practice has shown that stratifying students with "study for learning" is a very effective way to improve teaching quality, and has trained a large number of excellent talents that adapt to the characteristics of agricultural colleges and universities.

\section{Teaching in Different Levels: Grasping the construction of professional connotation and improving the effectiveness of different professional layered teaching. \\ For students of different majors, their requirements for mathematics knowledge are significantly different. Therefore, in teaching design, we must fully grasp the orientation of students in different majors and the needs of the discipline itself, and choose one that can meet the professional}


requirements of students. It can also promote the best teaching design for different levels of student development. For each class of mathematics, teachers should mobilize the enthusiasm and initiative of students at all levels as far as possible, form a good interaction between teachers and students, allow students to fully integrate into the entire classroom teaching process and deeply understand the application of mathematics. The combination of teaching and learning, the combination of movement and static, and the participation of students in all fields are all the basic requirements that we put forward when teaching mathematics courses in agricultural universities. In addition to teaching at the same time, we also use the expertise of our school in animal science, genetics and breeding, agronomy, ecology, and other specialty disciplines to combine it with knowledge of mathematics and statistics so that students at all levels are able to participate in these disciplines. Combining research and practice in related fields, the math team of our school presided over the completion of the Jiangxi provincial-level research project "Banner and Higher Level Stratified Cooperative Teaching Research", which provides a good summary of the research on stratified teaching areas. Of course, the professional connotation of hierarchical education cannot be separated from the subject assessment mechanism. That is, the educational administration system of higher agricultural colleges needs to set up an advanced evaluation system to make public and scientific teaching quality, teaching staff, scientific research projects and student learning effects. Inspections and assessments will mobilize the enthusiasm of professional construction and achieve the goal of "a strong foundation and strong ability" for the discipline itself [9].

\section{Hierarchical Evaluation: Promote innovation in distinctive fields and organic integration with other fields.}

In the implementation process of layered teaching, it is necessary to conduct a comprehensive evaluation of the learning effects of students at all levels in a timely, accurate and objective manner in order to sum up experience and improve teaching methods [10]. The three principles of layered evaluation here are differences, timeliness, and encouragement. The implementation of the layered teaching still insists on teaching in the original class, but the teacher will determine the evaluation criteria for the students' learning effect from the differences in the students' levels and results, so that a student with a basic level of mathematics can also find their own specialty and the field and stage to show their advantages. In the long-term teaching practice, we have summarized three ways to measure student stratified learning effects: questioning, assessment, and selection. Investigate students' knowledge of current knowledge by asking questions, test students' mastery of comprehensive knowledge through regular assessments, identify outstanding students through selection, and encourage them to integrate mathematical knowledge with their own areas of interest. Use mathematical modeling to do some practical investigation and research. Through different evaluation results, targeted communication and counseling are conducted for students at all levels so that they not only achieve good results, but also develop well in other fields.

\section{E. Stratified Improvement: Emphasis on the cultivation of practical ability and promote the improvement of performance in other disciplines.}

Evaluation is not an end. Our ultimate goal is to improve students' mathematics achievement and their ability to use mathematics knowledge to solve problems through hierarchical evaluation. According to the objective evaluation results of the students' learning process, the problems encountered in the layered teaching are found out and summed up in a timely manner, and reasonable solutions are found for improvement. Since students at all levels have set their own learning objectives within the stratum, students who have not completed the goals within the stratum must find out the causes in a timely manner and correct them, so as to fully solve their own difficulties in learning and not to make The problem has become more accumulative; at the same time, attention has been paid to discovering some students' knowledge advantages in a timely manner and encouraging mutual help and cooperation among students at different levels. In the process of stratification and improvement, we must pay attention to the cultivation of students' practical ability, so that students at all levels can develop their personal strengths, and achieve a combination of teaching students according to their aptitude and focusing on practice. In accordance with the students' own characteristics, the mathematics knowledge is closely combined with their professional disciplines, and targeted education and teaching are conducted so that the teaching process is consistent with the learning objectives of the major students as much as possible, and the students are continuously promoted in the teaching practice, professional performance and practical ability.

\section{IMPLEMENTATION PLAN}

\section{A. In teaching methods, use "layered cooperation."}

This is a teaching model of hidden and stratified explicit grouping. For a natural professional class, the teacher divides the students into several classes by observing the students' mathematics foundation and understanding their interest in learning through classroom observation and testing and afterschool operations. Levels (such as A, B, and C levels), this layering is only the teacher's mind, students do not know. For example, when organizing classroom teaching, students in a class may be divided into 3 to 5 groups. Students in each group have students at all levels to conduct cooperative learning together. This kind of teaching method takes the "stratified cooperation" into account for the students' individual differences and self-esteem. It also cultivates students' spirit of active learning and collaborative work, and lays a foundation for future teamwork to participate in mathematical modeling contests for university students. This student-centered teaching model gives full play to the role of mutual help, mutual assistance, and mutual learning among team members, and enables cooperative learning, so that students at all levels have greatly improved their academic performance. 


\section{B. In the teaching mode, highlight the "five-dimensional integration."}

In accordance with the basic teaching requirements and the characteristics of our school, we focused on the five main areas of layered teaching, from the five aspects of "adapting to the needs of social development, adapting to the characteristics of agricultural colleges, grasping the construction of professional connotations, promoting innovation in featured fields, and cultivating practical ability". The exploration and study of the "five-dimensional, one-level" teaching model has demonstrated the characteristics of higher agricultural institutions. On the one hand, for the professional students of higher agricultural colleges, they should develop their mathematical ideas and methods applied to agricultural technology, agricultural engineering, biotechnology, etc.; on the other hand, they should carry out the content and system of traditional university mathematics courses. Through optimization, reform, and innovation, the entire teaching content and system focus on broadening the basics, strengthening the application, and highlighting the practical aspects. While ensuring students fully understand the basic concepts, the introduction, argumentation, and promotion of important theorems have been strengthened, ensuring that the contents of the curriculum are popular. It's also easy to understand, easy to cultivate students' innovative thinking and self-learning ability.

\section{In teaching practice, adhere to the "various forms."}

Although theoretical teaching of mathematics is important, but at the same time that attention is paid to the teaching of mathematics theory, it is necessary to pay more attention to the cultivation of students' practical abilities. By carefully designing teaching content, combining theoretical knowledge with solving practical problems, students' interest in in-depth learning of mathematics knowledge can be stimulated. . In the teaching of mathematics courses, the mathematical modeling thoughts are subtly integrated into them, and the particularities of mathematical modeling are fully grasped. Based on the implementation of the "five-dimensional integration" teaching, problem-driven and interest-based incentive methods are adopted. , organize teachers and students to collect a large number of practical problems in the fields of life, information, engineering, environment, materials, energy, economy, finance, etc., and translate them into various types of mathematical modeling problems, using problem-driven The method mobilizes the enthusiasm of students at all levels to study mathematics, thereby cultivating students' ability to solve practical problems through mathematical logic analysis. In addition, a variety of mathematics experiment classes have been set up to suit the needs of students from different subjects in our school. In the first category, "Mathematics Experiments" is generally set up in engineering majors and it is used in conjunction with modeling theory teaching. It is used as a basic requirement for all engineering undergraduate students; the second category is for all majors in the school. The "Mathematical Modeling" elective courses are set up for students in the second and third grades to improve their ability to apply a variety of mathematical knowledge and other knowledge to solve practical problems. The third category is to rely on the platform of the National Undergraduate Mathematical Modeling Contest. And selected a group of outstanding students to participate in mathematical modeling contest, and constantly cultivate and enhance their practical ability and innovation ability.

\section{In teaching resources, strengthen the construction of teaching materials and online courses.}

The mathematics curriculum is an important basic compulsory course for the vast majority of students in agricultural colleges and universities. It involves a large scale; and the mathematics curriculum content is abstract and the academic hours are tight. Relying on classroom teaching, it is difficult to achieve satisfactory teaching results. Therefore, according to the basic requirements for "Mathematics Syllabus for 21st Century Colleges and Universities", we can prepare college mathematics textbooks adapted to the characteristics of agricultural colleges. The textbooks should pay attention to enhancing the students' awareness of "use" mathematics and train students to "use" mathematics. Ability, especially the application of calculus in agricultural sciences, life sciences, and agricultural economics management, such as the Logistic growth model, predator-prey model, staged loan repayment model, inventory-cost model, etc. Students have a preliminary understanding of the mathematical model, feel the usefulness of mathematics, and realize that "mathematics is on our side". At the same time, in order to promote the smooth implementation of the reform of mathematics teaching, it is necessary to strengthen the construction of teaching materials and vigorously strengthen the construction of online courses. Through the use of online teaching, it provides effective means and conditions for layered teaching and personalized teaching in each class.

\section{PRActical Results}

After the "five-dimensional" teaching practice in a layered manner, the concept of the teacher's education concept has undergone great changes. When teachers exchanged teaching experience in teaching seminars, they always complained that students' mathematics foundation is poor and their learning attitudes are not serious. Now they all change. In an effort to improve their own teaching methods, they explored "how to adopt more rational teaching design and teaching methods for different levels of students and improve the quality of mathematics teaching”. At the same time, the teachers give full recognition to the progress made by students at different levels. They also engage in in-depth and meticulous exchanges and talks with students who have difficulties in learning, understand their ideological trends in a timely manner, and encourage them to make greater progress through their efforts. Through the layered teaching practice of the mathematics curriculum, the relationship between teachers and students is harmonious and harmonious. The mathematics classroom becomes the classroom that the students like and the math teacher becomes a teacher that is welcomed and loved by the students. Practice has proved that the implementation of the "five-dimensional" layered teaching has trained and created a team of teachers who can both teach and educate people. 


\section{INNOVATION AND APPLICATION}

The research and practice process of the goal-driven "fivedimensional" layered teaching model conducted by our university involves multiple professional students and multiple management departments of the school. The research content and scope are relatively extensive. Based on the previous research of experts and scholars, we have done some unique and innovative work. In terms of features, compared with the past, research was conducted separately from five different aspects based on goal-driven, so that the categories of layered teaching were more detailed; compared with other universities, the "five-dimensional" layered teaching model was integrated into the adaptation. In the hierarchical teaching of the mathematics course featured by agricultural universities, the uniqueness of agricultural colleges and universities is reflected. In terms of innovation, based on student-oriented and mathematical quality education as the guideline, we propose a new goal-driven "five-dimensional, one-level" layered teaching model to cultivate innovative talents adapted to the characteristics of agricultural colleges and universities; The organic combination of teaching and improving the quality of students and the quality of personnel training put forward new insights and implementation methods.

The implementation of the "five-dimensional integration" type of hierarchical teaching can not only improve students' mathematics achievement at all levels, but also teach students in accordance with their aptitude, focus on the development of students' individuality, attach importance to the cultivation of practical abilities, and strengthen students' mathematics quality education. The set of methods and systems that have now been formed have had a positive impact on universities both inside and outside the province. Through the School of Science at our school, we held a seminar on mathematics teaching in agricultural universities in East China. The mathematics teachers and leaders attending the conference heard the experience of the five-dimensional teaching reform in mathematics courses in agricultural colleges and universities led by our leaders and teachers. The effect of the school teaching reform is highly affirmed; there are also many college mathematics teachers in the province to our college for the exchange of experience in mathematics teaching reform [11]. They all agreed that the research results of our university can be extended to other disciplines of agricultural universities; at the same time, this result can also serve as a good reference or reference for the teaching reform of mathematics courses in finance and economics or normal colleges and universities.

\section{SUMMARY}

Strengthening the teaching reform of mathematics courses in higher agricultural colleges and universities plays a very important role in improving the quality of talent cultivation in agricultural colleges and universities, and even promoting the development of agricultural economy. At the same time, this university's education reform is a systematic and complex project. Efforts to improve the quality of mathematics education in colleges and universities are essential for every one of our mathematics educators. This requires not only math teachers but also students and our cooperation, all levels of school leaders and colleges fully support. With a view to continuous exploration and practice, we can improve the agricultural colleges and universities teaching quality and quality of personnel training a more force.

\section{REFERENCES}

[1] Higher Education Quality Report [N]. Xinhua News Agency, 2016-0407.

[2] Li Xiaojing. Practical Research on Classroom Teaching in Classroom Guided by Problem [D]. Nanjing Normal University, 2010. (In Chinese)

[3] Flexner A. Medical education in Europe: a report to the Carnegie Foundation for the Advancement of Teaching[M]. Carnegie Foundation for the Advancement of Teaching, 1912.

[4] Lu-yu G. Research and Practice on College Maths Classification and Stratification Teaching [J]. Coal Technology, 2006, 4: 064.

[5] Yang Xiaoping, Liu Deqin, Mi Shaojun, et al. Deep Thinking and Practice of Gradation Teaching in Higher Mathematics[J]. College Mathematics, 2003, 19(6): 27-31.(In Chinese)

[6] Li Songhua, Sun Mingbao, Tu Jianbin. Research and practice of hierarchical teaching reform in mathematic analysis course of local undergraduate colleges [J]. Journal of Hunan Institute of Science and Technology: Natural Science Edition, 2012, 25(3): 89-91. (In Chinese)

[7] Xiong Rongsheng, He Weixiang. Research on the Necessity and Feasibility of Implementing Delamination Teaching in Higher Vocational Colleges (1)[J]. Journal of Zhejiang Business Technology Institute, 2004, 3(3): 62-66. (In Chinese)

[8] Xiong Rongsheng, He Weixiang. Research on the Necessity and Feasibility of Implementing Hierarchical Teaching in Higher Vocational Colleges (II)[J]. Journal of Zhejiang Business Technology Institute, 2004, 3(4): 65-68. (In Chinese)

[9] Zhou Jilin, Peng Bin, Gao Jiangyong. Thinking on the Optimization Strategy of "Integral and Multifaceted" Specialized Structural Chain in Higher Agricultural Colleges in China[J]. Higher Agricultural Education, 2014(3):14-18. (In Chinese)

[10] Li Yonghui. Application of Delaminated Progressive Teaching in Physics Student Experimental Teaching [D]. Tianjin Normal University, 2003. (In Chinese)

[11] Meng Xiangyan. A Preliminary Study on the Teaching Reform of Mathematics Series Courses in Agricultural Colleges [J]. Heilongjiang Higher Education Research, 2009 (9): 186-187. (In Chinese) 